\title{
EFFECT OF PH AND MOISTURE CONTENT ON CURRENT DENSITY OF IMPRESSED CURRENT CATHODIC PROTECTION : RESPONSE SURFACE METHODOLOGY STUDY
}

\author{
Dzulikram Baharuddin, Mohd Dinie Muhaimin Samsudin* \\ School of Chemical and Energy Engineering, Faculty of Engineering, Universiti Teknologi Malaysia, 81310 UTM Johor Bahru, Johor. \\ *Corresponding author email: dinie@utm.my
}

This is an open access article distributed under the Creative Commons Attribution License, which permits unrestricted use, distribution, and reproduction in any medium, provided the original work is properly cited

\section{ARTICLE DETAILS}

\section{Article History:}

Received 10 May 2018 Accepted 6 Jun 2018 Available online 10 July 2018

\section{ABSTRACT}

This study is based on one of the corrosion control which is cathodic protection on impressed current cathodic protection (ICCP). The purpose of this study is to investigate the effect of $\mathrm{pH}$ and moisture content on corrosion current density of ICCP for carbon steel pipe. Several factors could affect the corrosion current density including $\mathrm{pH}$ and moisture content of the soil. This study will be conducted by investigate the effect of these variables on current density using one-factor-at-a-time (OFAT) method and response surface methodology (RSM) via face centered central composite design (FCCCD) using Design-Expert 6.0.6 software. The results of this study is analyses via analysis of variance (ANOVA) and used to illustrate the interactions between variables on current density by graphical, equation and modeling which are response surface plots (three-dimensional plots-3D) and contour plots (two-dimensional plots-2D).

\section{KEYWORDS}

Current density, impressed current cathodic protection (ICCP), one-factor-at-a-time (OFAT), response surface methodology (RSM), cathodic protection.

\section{INTRODUCTION}

Underground metal structures are generally expected to have a long operational life, frequently 50 to 100 years. Metal structures such as natural gas, crude oil and water pipelines are only some of the many structures reported to have been affected by soil corrosion around the world [1]. In term of financial and costing, cost of the corrosion has been estimated around $\$ 300$ billion annually in the United States included the cost of failures, capitals and operations and maintenances [2]. Basically, it takes high cost to repair the damages and losses, and surely it has some methods to protect the material and need to be carried out in order to minimize the corrosion rate.

Corrosion is defined as a natural process occurs when metals return to their original state through a chemical reaction known as oxidation. This damage is one of the leading causes affecting the pipelines to leak and rupture. It also weakens the material strength and causes the material to fail and break down. In order to avoid and prevent metal from corrosion, several methods might be generally used to protect materials such as coating and cathodic protection method [3]. There are two types of cathodic protection methods which are impressed current cathodic protection (ICCP) and sacrificial anode. These methods are effective electrochemical techniques for reducing or preventing metal structures from being corroded by minimizing the difference in potential between anode and cathode, and commonly used in big structures or material protections [4].

It has been a challenge since the last few decades to study and investigate the factors affecting the current density of ICCP required to maintain the metals at the correct protection potential. Several factors need to be considered and measured which affecting the current density requirement such as $\mathrm{pH}$ and moisture content [5]. A large quantity of experiments, tests and analysis have been conducted by the researchers [4-7]. Nevertheless, the interactions between these variables such as $\mathrm{pH}$ and moisture content towards current density on ICCP has not yet been fully developed.
The objective of this study is to investigate the effect of $\mathrm{pH}$ and moisture content on current density requirement of ICCP using one-factor-at-a-time (OFAT) and response surface methodology (RSM). In conservative OFAT aspect, the corrosion factors are used by changing only one factor while holding the other factors to be constant. This approach is easiest and simplest to apply and mostly helps in selection of significant parameters affecting the current density requirement. However, this method is not only time restrictive, but also ignore the combined interaction among factors [8].

Conversely, the statistical RSM is a useful model for simultaneously studying the effect of several factors influencing the current density requirement. The other advantage of RSM is reduces the number of experiments required. The use of factorial designs and regression analyses for generating empirical models make RSM a good statistical tool [9].

\section{EXPERIMENTAL}

\subsection{Experimental Design}

In this study, the type of pipe used was carbon steel pipe (schedule 40 pipe dimension) as a structure or specimen with $3 / 4$ inch size, $26.67 \mathrm{~mm}$ external diameter, $20.93 \mathrm{~mm}$ internal diameter, $2.87 \mathrm{~mm}$ nominal thickness and $1400 \mathrm{~mm}$ length including the fitting. The type of anode electrode used was platinum and the reference electrode was copper in copper (II) sulfate $\left(\mathrm{Cu} / \mathrm{CuSO}_{4}\right)$. The mass of sieved sand was $6.00 \mathrm{~kg}$ with diameter range of $0.105-0.250 \mathrm{~mm}$.

Many physical and chemical parameters influenced current density requirement. The effect of $\mathrm{pH}$ and moisture content on current density requirement were investigated using OFAT method and RSM via FCCCD in order to get the interaction effect of those two variables on current density requirement. 


\subsection{Sample Preparation}

A carbon steel pipe as structure/specimen electrode was polished by using sand paper. The dimension of carbon steel pipe was measured and the total surface was calculated. Then, it was connected to the structure/specimen point on direct current (DC) feeder panel by using a wire connector. The reference electrode $\left(\mathrm{Cu} / \mathrm{CuSO}_{4}\right)$ was connected to the reference point. An anode electrode (platinum) was connected to anode point. The carbon steel electrode, reference electrode and anode electrode were submerged into a container that contained the dry sieved sand.

Then, natural electrode potential reading was recorded on both panels (measure panel and DC feeder panel) of cathodic protection training bench. The constant potential control was chosen and set rather than constant current control/limited voltage control. Base current and protection potential were set to zero and the value of output current and output voltage were maximized. The potential criterion was set to $0.85 \mathrm{~A}$ based on National Association of Corrosion Engineers (NACE) standard RP0169 [10]. The impressed current (A) and potential value (V) were recorded immediately. The polarization test was started at time interval of 3 seconds when the readings were constant to make sure that the electrode has been fully polarized. The current and potential value were taken once a stable potential was achieved.

\subsection{1 $p H$}

$\mathrm{pH}$ was adjusted by using $1.0 \mathrm{M}$ sodium hydroxide $(\mathrm{NaOH})$ and $0.1 \mathrm{M}$ hydrogen chloride $(\mathrm{HCl})$ solutions and determined by using digital $\mathrm{pH}$ meter.

\subsubsection{Moisture Content}

The moisture content from the total mass of solution which is $6.0 \mathrm{~kg}$ of sieved sand and tap water was used and the percentages of moisture content were measured by using Equation 1.

$$
\begin{gathered}
\frac{\text { mass, } m(\mathrm{~kg}) \text { of water }}{\text { mof sieved sand }+ \text { mof water }} \times 100 \% \\
=\text { Percentages }(\%)
\end{gathered}
$$

2.3 Study on the effect of variables on the current density requirement using one-factor-at-a-time (OFAT) method

The experimental design using OFAT method is shown in Table 1 . The effect of each factors on ICCP were evaluated, and the conditions were selected based on experimental results and trends.

\subsection{Study on the effect of variables on current density requirement using response surface methodology (RSM) via face centered central composite design (FCCCD)}

The results obtained from the OFAT method served as a preliminary work to set the ranges and levels of each factor for RSM study as shown in Table 2. The levels of each factor were coded as $-1,0$ and $1 . \mathrm{pH}$ and moisture content were coded as A and B, respectively. A complete design matrix, consisting 13 experimental runs is shown in Table 3 together with the variations of two factors.

Table 1: The experimental design using OFAT method

\begin{tabular}{llll}
\hline Factor studied & Run & pH & Moisture Content (\%) \\
\hline \multirow{3}{*}{ Effect of pH } & 1 & 3.00 & 20 \\
& 2 & 5.00 & 20 \\
& 3 & 7.00 & 20 \\
& 4 & 9.00 & 20 \\
\hline \multirow{2}{*}{ Effect of Moisture Content } & 5 & 11.00 & 0 \\
& 6 & 7.00 & 10 \\
& 7 & 7.00 & 20 \\
\end{tabular}

The experimental data was fitted to seven types of model which were mean, block, linear, two-factor interaction (2FI), quadratic and cubic polynomials. The good model to represent the effect of all factors was selected based on several factors including [11]: (i) the highest order polynomial model where the additional terms were significant, (ii) the model with insignificant lack-of-fit, (iii) low standard deviation $(S D)$, high $R$-squared (raw, adjusted and predicted) and low predicted residual sum of squares (PRESS).
Table 2: Experimental range and the levels of the two independent variables employed in RSM in terms of actual and coded factors.

\begin{tabular}{llllll}
\hline Factor & Coding & Unit & \multicolumn{2}{l}{ Level } \\
\cline { 3 - 5 } & & & $\mathbf{- 1}$ & $\mathbf{0}$ & $\mathbf{1}$ \\
\hline $\mathrm{pH}$ & $\mathrm{A}$ & & 5.00 & 7.00 & 9.00 \\
Moisture & $\mathrm{B}$ & $\%$ & 20 & 30 & 40 \\
\hline
\end{tabular}

Table 3: Experimental designs used in RSM studies

\begin{tabular}{lll}
\hline \multirow{2}{*}{ Run } & Factors & B \\
\cline { 2 - 3 } 2 & A & 30 \\
2 & 9.00 & 30 \\
3 & 5.00 & 30 \\
4 & 7.00 & 30 \\
5 & 7.00 & 40 \\
6 & 7.00 & 40 \\
7 & 5.00 & 20 \\
8 & 5.00 & 30 \\
9 & 7.00 & 40 \\
10 & 9.00 & 20 \\
11 & 7.00 & 30 \\
12 & 7.00 & 30 \\
13 & 7.00 & 20 \\
\hline
\end{tabular}


Then, the RSM results were analysed via analysis of variance (ANOVA) using Design-Expert 6.0.6 software. The significant model terms were selected based on the $P$ value with $95 \%$ confidence level. Model terms with $P$ value of more than 0.05 were considered as insignificant. The regression model for current density requirement was generated based on the significant terms $[8,12]$.

\subsection{Model Validation}

Three additional experimental runs as shown in Table 4 were carried out to compare the experimental data and predicted data within $90 \%$ confidence level used to calculate by using Design-Expert 6.0.6 software [12].

Table 4: Experimental runs of each factors on current density

\begin{tabular}{llll}
\hline Run & Goal & pH & $\begin{array}{l}\text { Moisture } \\
\text { Content (\%) }\end{array}$ \\
\hline 1 & In range & 6.00 & 25 \\
2 & In range & 6.00 & 35 \\
3 & In range & 8.00 & 35 \\
\hline
\end{tabular}

\section{RESULTS AND DISCUSSION}

\subsection{One-factor-at-a-time (OFAT) Analysis}

\subsubsection{Effect of $\mathrm{pH}$}

Based on Figure 1 presented the effect of $\mathrm{pH}$ on current density requirement on the carbon steel pipe at $20 \%$ of moisture content. The current density decreased with the increasing of $\mathrm{pH}$ until the $\mathrm{pH}$ at 7.00. After that, the current density showed an inward trend.

Acidic and alkaline solutions are more corrosive compared to neutral solution and might dissolve metals such as carbon steel pipe. As a consequence, it might increase the corrosion rate [13]. In addition, according to Kim et al., the current density requirement was affected by the presence of both atomic hydrogen or molecular hydrogen [14]. As a result, the current in cathodic protection was needed at high ampere to cover up the area of the metal as current density because of the presence of hydrogen in acid solutions [15].

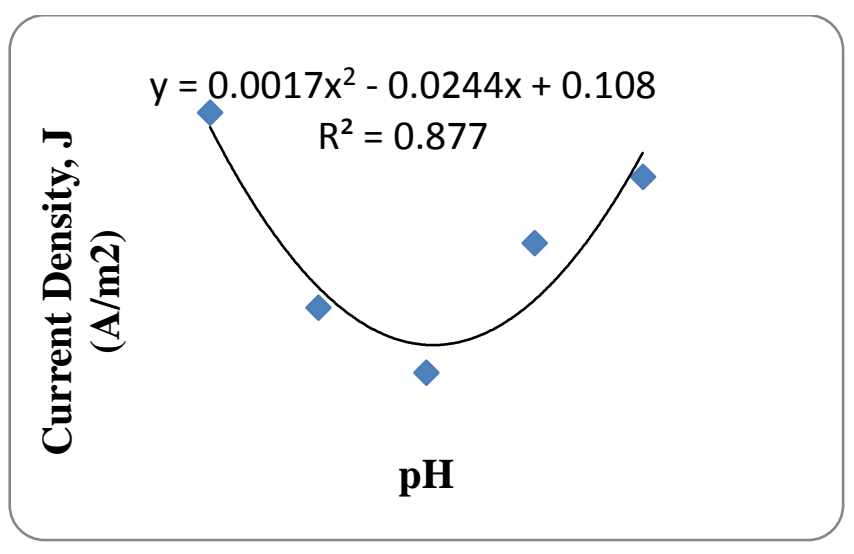

Figure 1: Effect of $\mathrm{pH}$ on current density

The model equation for regression model from this graph was defined and coefficients of the model equation were predicted and presented in Equation 2 as the relationship of the effect of $\mathrm{pH}$ and current density requirement.

Current density $\left(\mathrm{A} / \mathrm{m}^{2}\right)=$

$(0.0017)(p H)^{2}-0.0244(p H)+0.108$

\subsubsection{Effect of Moisture Content}

Figure 2 shows the effect of moisture content at different percentages to the current density on the carbon steel pipe at $\mathrm{pH}$ 7.00. The current density increased with the increase of moisture content until it was at 30\%. After that, the trend was keep constant and no change for the current density. It shows that the current density in moisture condition was higher than in case of dry. This might due to water served as electrolyte and current will flow directly [16].

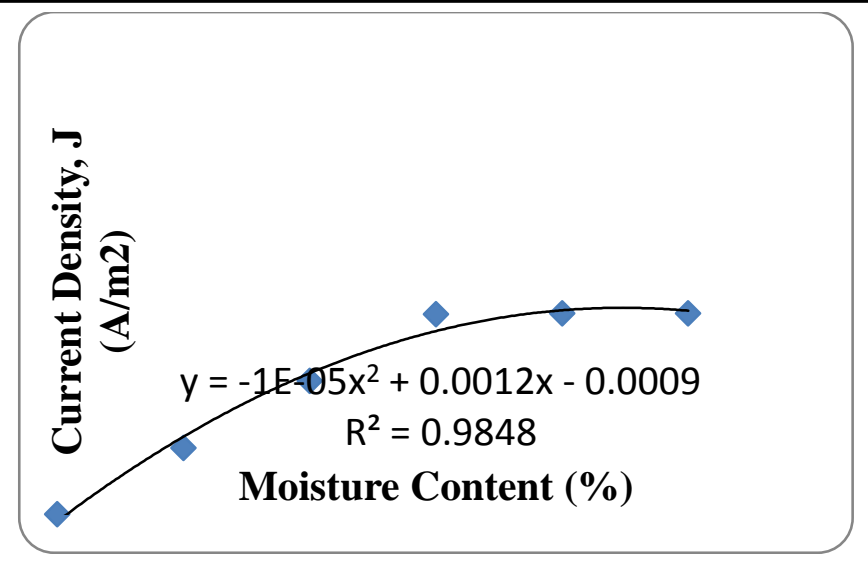

Figure 2: Effect of moisture content on current density

Water is a part of essential electrolyte required for electrochemical corrosion reactions and prerequisite for functioning of corrosion cell. In this case, corrosion occurred importantly only if dissolved oxygen was also present. Water rapidly dissolved oxygen from the air, and this was the source of the oxygen required in the corrosion process. Water itself also dissociated to a small extent to produce equal quantities of $\mathrm{H}^{+}$and $\mathrm{OH}^{-}$ions [17]. Moisture content at $0 \%$ was shown that there was almost no current density due to no water and less rapidly dissolved oxygen.

According to Faught D, it shows that metals have been buried in a certain depth in the soil initially showed very high corrosion rates, and then constant corroding at certain depth and moisture content and also affected the current density [18].

The model equation for regression model was defined and coefficients of the model equation were predicted and presented in Equation 3 as the relationship of the effect of moisture content and current density requirement.

Current density $\left(A / m^{2}\right)=$

$\left(-1 \times 10^{-5}\right)$ (moisture content $)^{2}+0.0012$ (moisture content) $-0.0009$

\subsection{Response Surface Methodology (RSM)}

\subsubsection{Development of Regression Model Equation and Statistical Analysis}

The results of RSM are shown in Table 5 . The current density was taken as the response, $\mathrm{Y}$.

Table 5: Experimental design matrix

\begin{tabular}{ll}
\hline Run & Current Density $\left(\mathbf{A} / \mathbf{m}^{2}\right)$ \\
\hline 1 & 0.04324 \\
2 & 0.03454 \\
3 & 0.02592 \\
4 & 0.02601 \\
5 & 0.02609 \\
6 & 0.03454 \\
7 & 0.02592 \\
8 & 0.02609 \\
9 & 0.04349 \\
10 & 0.01731 \\
11 & 0.02601 \\
12 & 0.02609 \\
13 & 0.03462 \\
\hline
\end{tabular}

The best model polynomial model to describe the relationship of the factors to the response was quadratic regression model. It fulfilled all the good model criteria as stated in 2.4 subsection. The statistic summary for every model is shown in Table 6 . 
Table 6: Model summary statistics

\begin{tabular}{llllll}
\hline Source & $\begin{array}{l}\text { SD } \\
\mathbf{x 1 0}^{\mathbf{5}}\end{array}$ & $\boldsymbol{R}$-squared & Adjusted R-squared & Predicted R-squared & $\begin{array}{l}\text { PRESS } \\
\mathbf{x 1 0}^{7}\end{array}$ \\
\hline Linear & & & & \\
2FI & 679.10 & 0.3335 & 0.2002 & -0.2407 & 8584.00 \\
Quadratic & 715.80 & 0.3335 & 0.1114 & -0.9651 & 13600.00 \\
Cubic & 6.50 & 1.0000 & 0.9999 & 0.9998 & 1.14 \\
\hline
\end{tabular}

One of the criteria was the lowest $S D\left(6.50 \times 10^{-5}\right)$ that indicated the model deviate closed from the mean [19]. The highest values of $R$-squared (raw, adjusted, and predicted $)(1.0000,0.9999,0.9998)$ indicated the stronger model is and the better it predicts the responses [20]. For a good statistical model, the $R$-squared value should be close to one, the more fit the model is deemed to be [1]. The lowest PRESS $\left(1.14 \times 10^{-7}\right)$, which is a measure of how a particular model fitted each point in the design [21].

The response surface quadratic model via ANOVA is shown in Table 7. The model equation for quadratic regression model was defined and coefficients of the model equation were predicted. The model used was a full quadratic equation obtained from RSM via FCCCD in terms of actual factors are presented in Equation 4.

Current density $\left(\mathrm{A} / \mathrm{m}^{2}\right)=$

$+0.11764-0.043058(\mathrm{pH})+2.98820 \times 10^{-3}$ (moisture content)

$+3.22573 \times 10^{-3}(\mathrm{pH})^{2}-4.28707 \times 10^{-5}(\text { moisture content })^{2}$

$+3.12500 \times 10^{-6}(\mathrm{pH})$ (moisture content)

Table 7: ANOVA for response surface quadratic model

\begin{tabular}{|c|c|c|c|c|c|}
\hline Source & $\begin{array}{l}\text { Sum of Squares } \\
{\mathrm{x} 10^{4}}^{4}\end{array}$ & Degrees of Freedom & $\begin{array}{l}\text { Mean Square } \\
{\mathrm{x} 10^{4}}^{4}\end{array}$ & F Value & Prob $>$ F \\
\hline Model & 6.9180 & 5 & 1.3840 & 32752.74 & $<0.0001$ \\
\hline$A$ & 1.1570 & 1 & 1.1570 & 27391.58 & $<0.0001$ \\
\hline$B$ & 1.1570 & 1 & 1.1570 & 27225.50 & $<0.0001$ \\
\hline$A^{2}$ & 4.5980 & 1 & 4.5980 & 108840.99 & $<0.0001$ \\
\hline$B^{2}$ & 0.5076 & 1 & 0.5076 & 12015.36 & $<0.0001$ \\
\hline$A B$ & 0.0002 & 1 & 0.0002 & 3.70 & 0.0959 \\
\hline
\end{tabular}

\subsubsection{Effect of Process Variables on Current Density Requirement}

In the present study, RSM via FCCCD was utilised to model the effect of $\mathrm{pH}$ and moisture content on current density requirement. The quadratic polynomial model was suggested and statistically tested in the previous subsection. In this subsection, the interaction effects between factors on the responses were discussed.

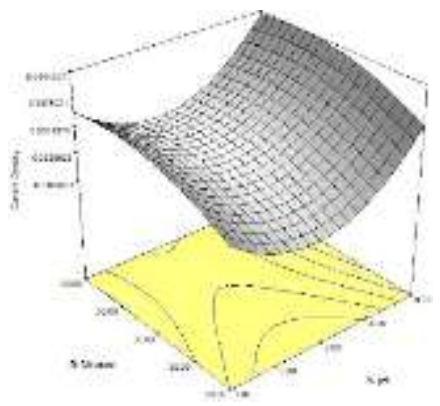

Figure 3: Response surface of current density as a function of $\mathrm{pH}$ and moisture content

The visualization of the predicted models (Equation 4) on the current density for the significant interaction terms is shown in Figure 3 and 4 in the form of response surface plot (3D) and contour plot (2D). The 3D plot showed the interaction between the independent variables and the responses, while 2D plot, line of constant response were drawn on the plane of independent variables.

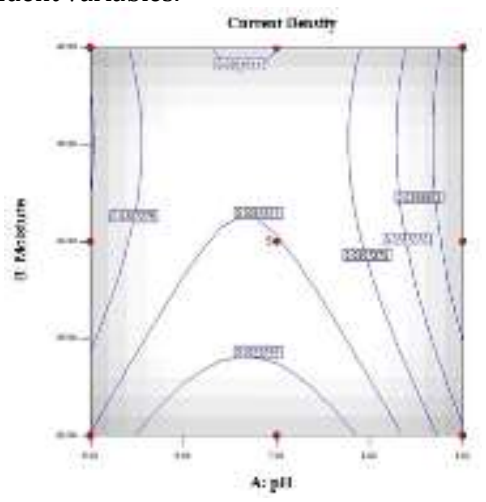

Figure 4: Contour plot of current density as a function of $\mathrm{pH}$ and moisture content
The 3D plot and 2D plot of interaction between $\mathrm{pH}$ and moisture content on the current density requirement were indicated by a saddle nature of contour plot. A saddle contour plot means a point at the origin of the surface that is a maximum response in one planar cross-section and a minimum response in another section [22]. A saddle point was observed in the central region over the contour [23]. It shown that the center of the saddle curve was the minimum response of the current density requirement was achieved as the $\mathrm{pH}$ at 6.85 and $34.72 \%$ of moisture content.

\subsection{Model Validation}

This study is to investigate the interaction effect of those two variables on current density requirement. Therefore, in order to validate these results, three additional experimental runs were carried out at various conditions. The result of validation runs were tabulated in Table 8. The mean and $S D$ of the experimental runs were calculated. In order to compare the experimental data and predicted data, the ranges of $90 \%$ confidence level were also determined. All the statistical data were calculated using IBM SPSS Statistics Version 23 software.

Table 8: Comparison between experimental and predicted data

\begin{tabular}{|c|c|c|c|}
\hline \multirow[t]{2}{*}{ Run } & \multicolumn{3}{|c|}{ Response: Current Density $\left(\mathrm{A} / \mathrm{m}^{2}\right)$} \\
\hline & Experimental & Predicted & $\varepsilon$ (error) \\
\hline 1 & 0.02292 & 0.02380 & -0.00080 \\
\hline 2 & 0.02823 & 0.02815 & 0.00008 \\
\hline 3 & 0.03325 & 0.03257 & 0.00068 \\
\hline Mean & 0.02813 & 0.02817 & -0.00001 \\
\hline \multicolumn{2}{|c|}{ Standard Deviation } & \multicolumn{2}{|c|}{0.00516} \\
\hline \multicolumn{2}{|c|}{ Range within $90 \%$ confidence level } & \multicolumn{2}{|c|}{$0.01942-0.03684$} \\
\hline
\end{tabular}

It was found that the mean was $0.02813 \pm 0.00871\left(\mathrm{~A} / \mathrm{m}^{2}\right)$. While the range of current density requirement within $90 \%$ confidence level was 0.01942 $\mathrm{A} / \mathrm{m}^{2}-0.03684 \mathrm{~A} / \mathrm{m}^{2}$. Since the predicted data were within the tested ranges, it can be concluded that there is no difference between the experimental values, and the predicted data within $90 \%$ confidence level and the current density requirement as suggested by RSM via FCCCD is valid.

\section{CONCLUSION}

This study was carried out to investigate the effect of $\mathrm{pH}$ and moisture content on current density requirement of ICCP using OFAT method and statistical tool, RSM via FCCCD. 
i) In OFAT method, the relationship between the effect of $\mathrm{pH}$ on current density requirement was:

Current density $\left(\mathrm{A} / \mathrm{m}^{2}\right)=$

$(0.0017)(p H)^{2}-0.0244(p H)+0.108$

and the relationship between the effect of moisture content on current density requirement was:

Current density $\left(\mathrm{A} / \mathrm{m}^{2}\right)=$

$\left(-1 \times 10^{-5}\right)$ (moisture content) ${ }^{2}+0.0012$ (moisture content) $-0.0009$

ii) While in RSM study, the interaction of the two factors ( $\mathrm{pH}$ and moisture content) on the current density requirement in model equation was:

Current density $\left(\mathrm{A} / \mathrm{m}^{2}\right)=$

$+0.11764-0.043058(\mathrm{pH})+2.98820 \times 10^{-3}$ (moisture content)

$+3.22573 \times 10^{-3}(\mathrm{pH})^{2}-4.28707 \times 10^{-5}$ (moisture content) $^{2}$

$+3.12500 \times 10^{-6}(\mathrm{pH})$ (moisture content)

The response surface plot and contour plot showed a saddle curve of interaction between effect of $\mathrm{pH}$ and moisture content on the current density requirement, which means that the center of the saddle curve and contour plot was the minimum response of current density requirement and achieved at $\mathrm{pH} 6.85$ and $34.72 \%$ of moisture content.

In order to validate the model, three sets of experimental runs were carried out and all the statistical data were calculated using IBM SPSS Statistics Version 23 software. The range of current density within $90 \%$ confidence level was $0.01942 \mathrm{~A} / \mathrm{m}^{2}-0.03684 \mathrm{~A} / \mathrm{m}^{2}$ and there is no difference between the experimental result and the predicted data within $90 \%$ confidence level and the current density requirement as suggested by RSM is valid.

\section{ACKNOWLEDGEMENT}

The author would like to express full acknowledgement for the support from Faculty of Chemical and Energy Engineering (FCEE) and Universiti Teknologi Malaysia (UTM) for making this study possible.

\section{REFERENCES}

[1] Baș, D., Boyacı, I.H. 2007. Modeling and optimization, I: Usability of response surface methodology. Journal of Food Engineering, 78 (3), 836845.

[2] Ajeel, S.A., Ali, G.A. 2008. Variable Conditions Effect on Polarization Parameters of Impressed Current Cathodic Protection of Low Carbon Steel Pipes. Eng. \& Tech, 26, 636.

[3] Ahdash, A.I. 2010. Design of impressed current cathodic protection for steel immersed in freshwater. Universiti Teknologi Malaysia, Faculty of Mechanical Engineering.

[4] Ahdash, A., Hamzah, E., Ourdjini, A., Shamsuri, S.R. 2013. Effects of Cathodic Protection and Coating on the Corrosion Rate of Carbon Steel in Stagnant and Flowing Freshwater. Advanced Materials Research, 686, 219-226.

[5] Ismail, A.I.M., El-Shamy, A.M. 2009. Engineering behaviour of soil materials on the corrosion of mild steel. Applied Clay Science, 42 (3-4), 356-362.

[6] Lu, X. 2005. The risk for heavy metal mobility from corrosion products to soil and groundwater. Trita-lwr Master Thesis.

[7] Setoudeh, M. 2012. Experimental Study of Factors Affecting Corrosion in Gas Wells Using Potantio Acetate and Galvan Acetate Tests. International Journal of science and investigations, 13-16.

[8] Singh, S.K., Tripathi, V.R., Khare, S.K., Garg, S.K. 2011. Comparative onefactor-at-a-time, response surface (statistical) and bench-scale bioreactor level optimization of thermo alkaline protease production from a psychrotrophic Pseudomonas putida SKG-1 isolate. Microb Cell Fact, 10 (1), 114-127.

[9] Doddapaneni, K.K., Tatineni, R., Potumarthi, R., Mangamoori, L.N. 2007. Optimization of media constituents through response surface methodology for improved production of alkaline proteases by Serratia rubidaea. Journal of Chemical Technology and Biotechnology, 82 (8), 721729 .

[10] RP, N. 2005. Recommended Practice: Control of External Corrosion on Underground or Submerged Metallic Piping Systems. NACE International, Houston.

[11] Myers, R.H., Montgomery, D.C., Anderson-Cook, C.M. 2009. Response surface methodology: process and product optimization using designed experiments. 705, John Wiley \& Sons.

[12] Coleman, H.W., Steele, W.G. 2009. Experimentation, validation, and uncertainty analysis for engineers. John Wiley \& Sons.

[13] Elsener, B., Bertolini, L., Pedeferri, P., Polder, R.B. 2013. Corrosion of steel in concrete: prevention, diagnosis, repair. John Wiley \& Sons.

[14] Kim, S.J., Jang, S.K., Kim, J.I. 2008. Investigation on optimum corrosion protection potential of $\mathrm{Al}$ alloy in marine environment. Materials SciencePoland, 26(3)

[15] Shreir, L.L. 2013. Corrosion: corrosion control. Newnes.

[16] Han, M.H., Lee, H.S. 2008. An Experimental Study on the Application of Cathodic Protection Method Applying Zn-Al Metal Spray on the RC Structure. Key Engineering Materials, 385-387, 665-668.

[17] Kritzer, P. 2004. Corrosion in high-temperature and supercritical water and aqueous solutions: a review. The Journal of Supercritical Fluids, $29(1-2), 1-29$.

[18] Faught, D. 2006. AC/DC interference corrosion in pipelines. Summary Report, MetriCorr.

[19] Feng, Y., Cai, Z., Li, H., Du, Z., Liu, X. 2013. Response surface optimization of fluidized roasting reduction of low-grade pyrolusite coupling with pretreatment of stone coal. Journal of Mining and Metallurgy B: Metallurgy, 49 (1), 33-41.

[20] Pongstabodee, S., Monyanon, S., Luengnaruemitchai, A. 2012. Applying a face-centered central composite design to optimize the preferential $\mathrm{CO}$ oxidation over a $\mathrm{PtAu} / \mathrm{CeO} 2-\mathrm{ZnO}$ catalyst. International Journal of Hydrogen Energy, 37 (6), 4749-4761.

[21] Beg, Q.K., Sahai, V., Gupta, R. 2003. Statistical media optimization and alkaline protease production from Bacillus mojavensis in a bioreactor. Process Biochemistry, 39 (2), 203-209.

[22] Baelus, B., Peeters, F., Schweigert, V. 2001. Saddle-point states and energy barriers for vortex entrance and exit in superconducting disks and rings. Physical Review B, 63 (14), 144-517.

[23] Marble, A.E., Mastikhin, I.V., Colpitts, B.G., Balcom, B.J. 2007. A compact permanent magnet array with a remote homogeneous field. Journal of Magnetic Resonance, 186 (1), 100-104. 